\title{
THE RECENT LIGHTCURVE OF 3C 345
}

\author{
K.J. SCHRAMM ${ }^{1}$, U. BORGEEST ${ }^{2}$ and J. V.LINDE ${ }^{2}$ \\ ${ }^{1}$ Université de Liège, Inst. d'Astrophysique, Belgium \\ ${ }^{2}$ Hamburger Sternwarte, Germany \\ and
}

S.J. WAGNER and J. HEIDT

Landessternwarte Heidelberg, Germany

\begin{abstract}
We present the lightcurve of $3 \mathrm{C} 345(1641+399, z=0.595)$ in Johnson $R$. The data until summer 1992 are analysed and discussed in detail in Schramm et al. (A\&A, Nov. 1993). The more recent lightcurve is almost flat $(R \simeq 16.9)$, giving new constraints on variability models, see Camenzind, this proceedings.
\end{abstract}

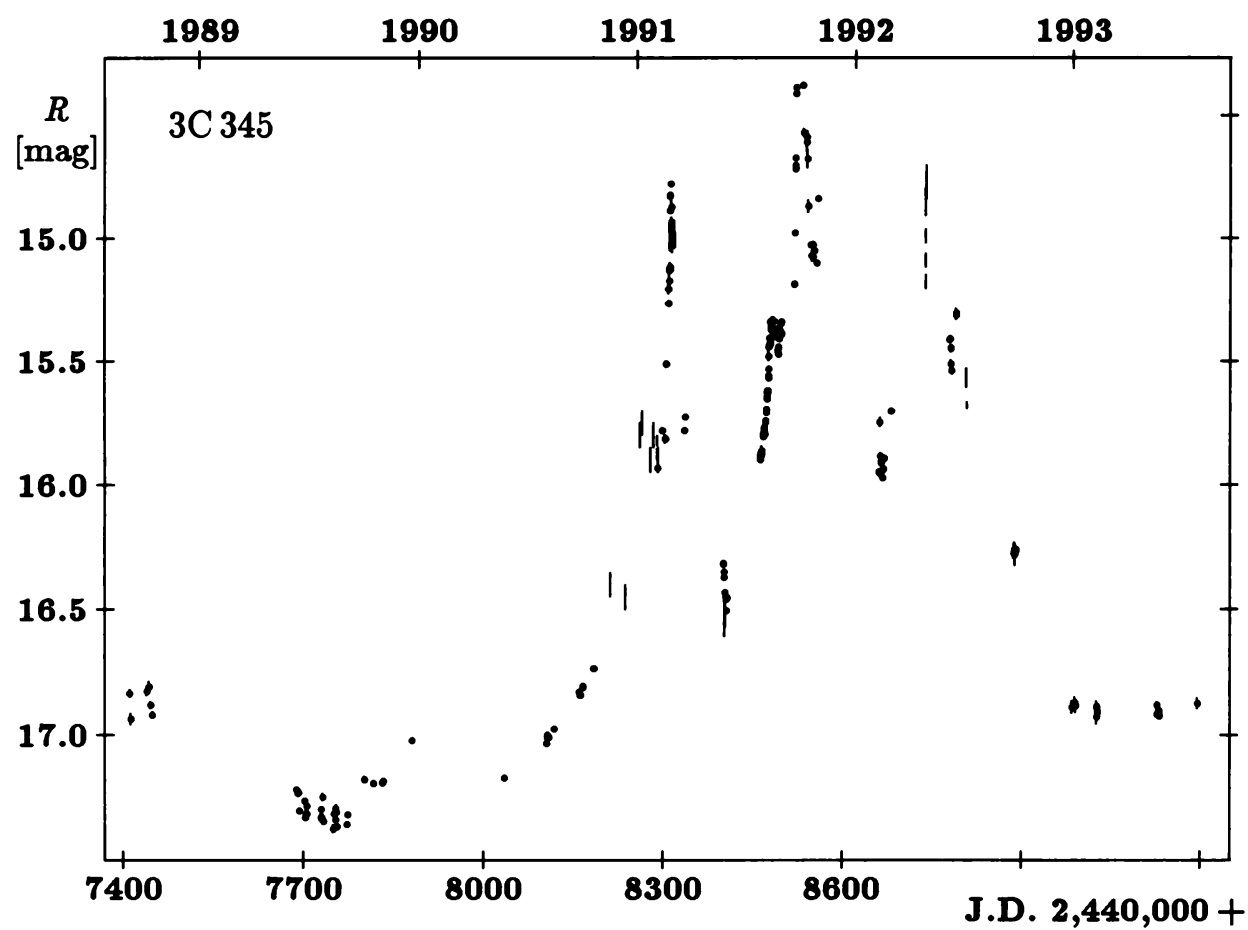

Fig. 1. Dots: data collected at Calar Alto, Spain, or LSW Heidelberg; data from other observers (for refs. see Schramm et al.) are indicated by the error bars only.

\section{References}

Schramm K.-J., Borgeest U., Camenzind M., Wagner S.J. et al., 1993, A\&A, to appear in Nov. 93 391

T. J.-L. Courvoisier and A. Blecha: Multi-Wavelength Continuum Emission of AGN, 391.

(C) 1994 IAU. Printed in the Netherlands. 